\title{
The Glucocorticoid Receptor in Retroviral Infection
}

\author{
Victor Solodushko and Brian Fouty \\ University of South Alabama, \\ U.S.A.
}

\section{Introduction}

The hope that delivering genes to ailing tissues and organs can treat disease more effectively than drugs or surgery, has fueled the intense interest in gene therapy. Potential uses of gene therapy include replacing mutated genes with healthy ones, inactivating improperly functioning mutated genes, or introducing new genes into the body to help fight a specific disease. While the concept of gene therapy is easy to understand, technical difficulties have limited its practical use. Delivered genes that function admirably in cell culture may not function correctly in vivo, may have unexpected consequences on intracellular signaling pathways, or may transform cells raising the risk of iatrogenic malignancy.

Retroviruses play a central role in gene delivery applications because they have a high infection efficiency and are able to induce stable mutagenesis in eukaryotic cells (Yi et al., 2005; Somia \& Verma, 2000; Thomas et al., 2003). Stable incorporation of retroviral DNA into the host genome is advantageous, since long-term expression of the transgene, usually a requirement for prolonged therapeutic efficacy, is possible. While they are currently being used for in vitro and (animal) in vivo studies, the clinical use of retroviral vectors to deliver genes is still in its infancy. Among the reasons for the slow progress in adapting retroviruses to deliver genes are the concerns over potential adverse events when introduced into humans and a limited understanding of the mechanisms that affect retroviral function and expression in infected (target) cells.

Both wild type and genetically modified retroviruses rely on the host cell to assist during its life cycle. Retroviral infection of cells, followed by integration of its genome into the host genome, is not always a certain process, however, and cellular and extracellular processes can influence these events. Therefore, while retroviral gene delivery is generally successful, the impact of viral infections on target cells remains less predictable and can be considered, basically uncontrollable. Despite the care with which viral vectors are generated, researchers ultimately rely on random events that can yield both positive and negative outcomes.

In most eukaryotic cells, steroid hormones regulate a wide variety of physiological functions ranging from inflammation to pregnancy. There are five major classes of steroid hormones: glucocorticoids, mineralocorticoids, estrogens, androgens, and progestins. Steroid hormones from each class can complex with their specific receptors, and often with other transcription factors, to recognize DNA sequences called response elements. This mechanism of gene regulation by steroids is so potent and universal throughout the biosphere that it is not surprising that retroviruses have exploited the host nuclear steroid receptor regulatory system to expand their own genomes and improve their overall functionality. 
While most steroid hormone receptor systems could be utilized by retroviruses during target cell infection, the strongest evidence exists for an important role of the glucocorticoid receptor (GR) in this process. This review focuses on the role of the nuclear glucocorticoid receptor in controlling retroviral infection and function and highlights its potential importance in retroviral-based gene therapy applications.

\section{Retroviral vectors for gene therapy}

Retroviruses belong to the family Retroviridae which consists of a large and diverse group of viruses classified into seven genera. Within each genera retroviruses are structurally and functionally similar and further classified based on a computer analysis of their genome. Only two of them, gamma-retroviruses and lentiviruses, are commonly used as vectors for gene therapy, however. The murine leukemia virus (MLV) is the prototypical gammaretroviral backbone that has been modified to generate different gene delivery vectors, whereas the human immunodeficiency virus type 1 (HIV-1) provides the standard backbone for most lentiviral vectors. Both types of retroviruses (gamma-retroviruses and lentiviruses) have been used to generate stable genetic modification in host cells through the chromosomal integration of the transferred vector genomes. This ability to stably modify target cell genomes is useful not only for research purposes, but also for clinical gene therapy strategies intended to correct genetic defects. An important difference between gamma-retroviruses and lentiviruses is that gamma-retroviruses can only infect dividing cells whereas lentiviruses can infect both dividing and quiescent cells. To date, gammaretroviral and lentiviral vectors have been used in more than 300 clinical trials targeting various diseases (Telesnitsky, 2010).

All retroviral genomes are non-segmented and typically consist of at least 4 genes: gag, pro, pol and env. The gag gene encodes the major structural polyprotein Gag which is both necessary and sufficient for the assembly of non-infectious and immature viral-like particles. The pro gene encodes the viral protease that is responsible for facilitating the maturation of viral particles. Products of the pol gene include reverse transcriptase, RNase $\mathrm{H}$ and integrase, all critical for the successful integration of the viral genome into the host genome. Env encodes the viral surface glycoprotein and transmembrane proteins that mediate cellular receptor binding and membrane fusion. There are additional genes (called accessory genes) that are present in some, but not all, gamma-retroviruses and lentiviruses. These accessory genes are involved in regulating the synthesis and processing of viral RNA and other replicative functions. For the HIV-1 based viruses, these additional genes include: Vif, Vpr, Vpu, Tat, Rev, and Nef (Malim \& Emerman, 2008).

The retroviral genome is flanked by two long terminal repeat (LTR) sequences at both the $5^{\prime}$ and 3 '- ends. In the integrated virus (provirus) each LTR consists of three regions: 1 ) the R sequence, 2) the U3 region, and 3) the U5 region. The $\mathrm{R}$ region is a short (18-250nt) sequence which forms a direct repeat at both ends of the genome, and is flanked upstream by the U3 region and downstream by the U5 region in the integrated virus. The U3 is a unique noncoding segment of 200-1,200nt that forms the $5^{\prime}$ end of the virus after reverse transcription. It contains the enhancer elements responsible for transcription of the integrated virus. The U5 is a unique, non-coding region of 75-250nt which is the first part of the genome to be reverse transcribed, forming the $3^{\prime}$ end of the provirus genome. Both U3 and U5 sequences are required for viral integration. The Primer Binding Site (PBS) is an 18nt sequence complementary to the $3^{\prime}$ end of the specific tRNA primer used by the virus to begin reverse 
transcription. Downstream from the PBS is the packaging signal ( $p s i)$ sequence that allows completed RNA transcripts to be packaged into budding viral cores. Polypurine Tract (PPT) is a short $(\sim 10 \mathrm{nt})$ run of $A / G$ residues responsible for initiating $(+)$ strand synthesis during reverse transcription. The 5' LTR is the control center for gene expression and contains both promoter and regulatory elements that can be responsive to both viral and cellular transactivating factors. The $3^{\prime}$ LTR functions as a transcription terminator and a polyadenylation signal that leads to the development of a mature viral transcript.

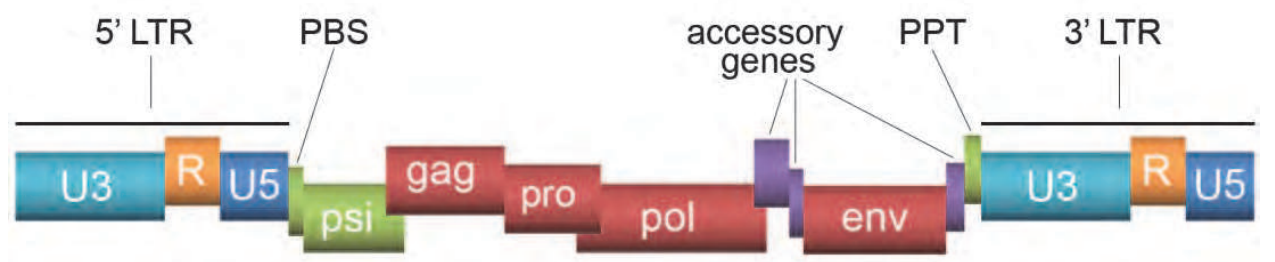

Fig. 1. Schematic representation of the retroviral genome.

For gene delivery applications both gamma-retroviral and lentiviral genomes are initially modified to meet certain criteria (Lech \& Somia, 2008). This includes removal of gag, pol and env to prevent the provirus from generating infectious particles in target cells. This makes them safer and therefore more suitable to deliver genes than wild type viruses. Other parts of the viral genome, such as PBS and PPT, cannot be removed if the vector is to remain functional, however. In addition, while both the LTRs and the psi sequence can be partially truncated or modified, they must be present for the virus to function.

A critical difference therefore, between wild type retroviruses and modified retroviruses used in research applications, is the ability of the wild type to generate infectious particles, a trait the retroviral vectors lack. The modifications required to make retroviruses safer, however, can impact enhancer and promoter elements within the LTR and thus make direct comparisons between the behavior of wild type and modified retroviral vectors difficult. Specific to this review, modifications within the LTR promoter of both gamma-retroviruses and lentiviruses can alter the activity of the nuclear GR-regulatory pathway, yielding potentially conflicting experimental results depending on the vector and cell type.

\section{Glucocorticoid receptor regulatory system}

The glucocorticoid receptor (GR) is also known as NR3C1 (nuclear receptor subfamily 3, group C, member 1) and is encoded by the NR3C1 gene located on chromosome 5 (5q31) in humans (Hollenberg et al., 1985; Francke \& Foellmer, 1989; Lu et al., 2006; Rhen \& Cidlowski, 2005). The GR is expressed in almost every cell in the body and upon binding to glucocorticoids, regulates genes controlling development, metabolism, and immune response.

In the absence of the glucocorticoid hormone, the GR resides, inactive, in the cytosol, complexed with a variety of proteins (Pratt et al., 2006). When glucocorticoids bind to the GR it can lead to either gene transactivation or gene transrepression (Buckingham, 2006; Hayashi et al., 2004). Transactivation usually involves homodimerization of the receptor followed by its translocation into the nucleus via active transport. The activated GR binds to specific DNA sequences called glucocorticoid response elements (GRE), which are short sequences of DNA within the promoter of a gene that are able to bind GR complexes and 
regulate transcription. The GRE's sequence is most commonly a pair of inverted repeats separated by a short linker, indicating that the receptor binds as a homodimer. Half-sites GRE are also present and usually bind monomeric GR. These half-sites are only weakly activated by GR complexes, but can also have inhibitory effects, leading to transrepression.

Nuclear factor-kappaB (NFkB) and the activator protein-1 (AP-1) are two important transcription factors that are negatively regulated by the nuclear GR signaling pathway. In the absence of activated GR, NFKB and AP-1 are able to translocate into the nucleus and transactivate target genes by binding to specific DNA sequences that correspond to each transcription factor. Activated GR can complex with either of these transcription factors, however, and prevent them from binding their target genes, repressing genes that are normally upregulated by NFKB or AP-1. GR-mediated transrepression of NFkB can also occur through $\mathrm{GR}^{\prime} \mathrm{s}$ binding to $\mathrm{NF \kappa B}$ 's response elements, thus preventing transactivation (Hermoso \& Cidlowski, 2003; Nissen \& Yamamoto, 2000; Tuckermann et al., 1999).

NFkB regulates the expression of well over 100 genes, the majority of which participate in the host immune response (Ghosh et al., 1998). These proteins include cytokines and chemokines, receptors required for immune recognition, proteins involved in antigen presentation, and adhesion receptors involved in transmigration across blood vessel walls. Because of its extensive role in immune action, NFkB has been termed the central mediator of the immune response (Hiscott et al., 2001). The ability of activated GR to block NFkB's transactivation of these genes is likely important in mediating the immunosuppressive effect of glucocorticoids (Ito et al., 2001).

GRE are present in the genomes of most gamma-retroviruses (Bruland et al., 2003a, Rodriguez \& Goff, 2010, Pages et al., 1995) and HIV-1 based lentiviruses (Ghosh, 1992; Mitra et al., 1995; Hapgood \& Tomasicchio, 2010). NFkB response elements are generally absent in gamma-retroviruses, but present in HIV-1, making GR-mediated regulation of lentiviral vectors derived from the HIV-1 backbone more complex. The presence of GRE and NFkB response elements in the retroviral genome suggests that glucocorticoids can exert influence on the viral-host cell interaction. Defining the role of GR on the retroviral lifecycle may not only provide clues on how to combat retroviral infections, but also provide alternate strategies for adapting retroviral vectors for gene delivery.

\section{Effects of activated glucocorticoid receptors on gamma-retroviral and lentiviral promoters}

The prominence of GRE in the gamma- and lentiviral genomes suggests that their life cycles are dependent on the host's GR regulatory system (Rusmevichientong \& Chow, 2010). Glucocorticoids stimulate gamma-retroviral promoter activity in multiple cell types. Synthetic corticosteroid hormones stimulated MLV transgene expression in primary bone marrow stromal cells (Jaalouk et al., 2000). The synthetic glucocorticoid, dexamethasone, increased gamma-retroviral LTR promoter activity in pulmonary artery endothelial and smooth muscle cells and also in 293 cells as evidenced by an increased expression of the reporter protein, GFP, in infected cells (Solodushko et al., 2009) Most published evidence suggests that the usual effect of glucocorticoids on gamma-retroviral promoter activity is positive (Mitra et al., 1995).

The effect of GR on the lentiviral promoter is more complicated than its effect on gammaretroviruses, however. Activation of the GR can enhance lentivirus functionality. H9V3 cells transfected with the reporter HIV-1 LTR did show increased transgene expression in the 
presence of glucocorticoids (Kolesnitchenko \& Snart, 1992). HIV-1 infected lymphoid and monocytoid cell lines treated with cortisol or dexamethasone also increased HIV-1 gene expression and virus production in vitro, a process that required the presence of the GRE (Soudeyns et al., 1993). In addition, glucocorticoid administration has also been associated with increased HIV-1 promoter activity leading to increased virus replication and AIDS progression in infected individuals (Kino et al., 2000; Soudeyns et al., 1993).

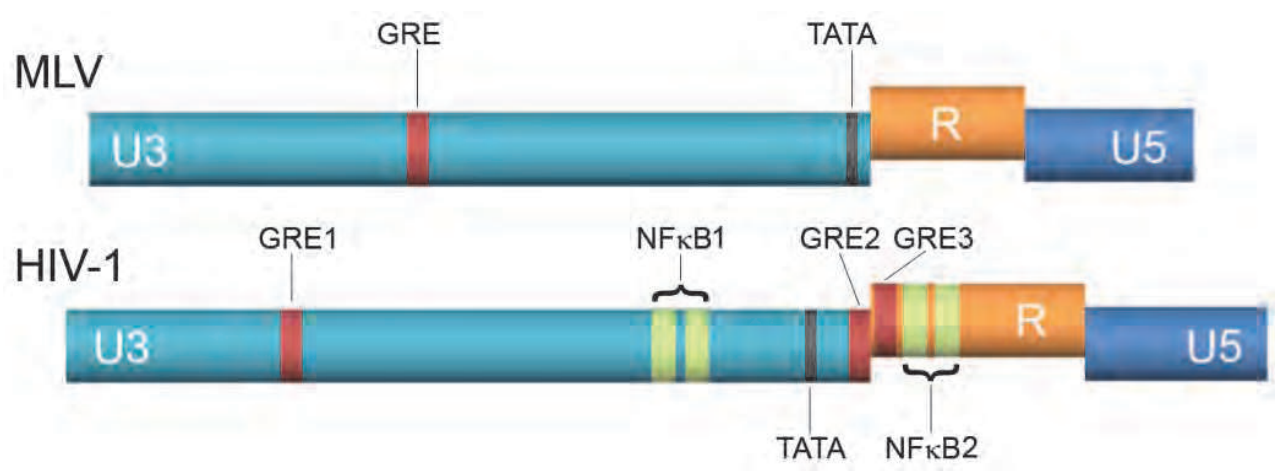

Fig. 2. Schematic representation of binding sites for activated GR in the LTR of MLV (gammaretrovirus) and HIV-1 (lentivirus). In MLV GR can bind GRE resulting in transactivation. In HIV-1 GR can bind GRE1 generally resulting in transactivation and GRE2 and GRE3 (both half sites) leading to transrepression. Activated GR can also directly interact with HIV-1 NFkB binding sites resulting in transrepression of the viral promoter.

Lentiviruses contain both stimulatory and inhibitory GRE sites though and therefore activated GR can cause different effects depending on the cell type. The first GRE (GRE1) is located between -264 and -259 relative to the transcriptional start site and can generally be considered a stimulatory GRE. The other GREs (GRE2 and 3) are half sites and are positioned between -6 and -1 and between +15 and +20 , respectively, relative to the transcriptional start site (Mitra et al., 1995; Berkhout et al., 1989). Both GRE half-sites (2 and 3) are shown to be negative regulators of the viral promoter (Meijsing et al., 2009).

In addition to its ability to signal through the GRE, the GR signaling pathway can also regulate lentiviral (although not gamma-retroviral) behavior through its interaction with the NFkB and AP-1 pathway. Activated GR can interfere with NFkB signaling either by directly interacting with NFkB response sites or by binding with NFkB proteins (thus blocking its ability to enhance the lentiviral LTR). As shown in figure 2 two NFkB response sequences (NFkB1) in the HIV-1 U3 region are located between GRE1 and the TATA box. Wild type HIV-1 that lacks both of the NFkB binding sites is replication-incompetent; returning one or both NFkB elements restores the virus's ability to replicate (Ross et al., 1991).

The active binding sites for NFkB, however, are not limited to the enhancing region but can be found downstream of the transcription initiation site. In addition to this double NFkB site in the U3 region, another double NFkB binding site is present in the $\mathrm{R}$ region of the

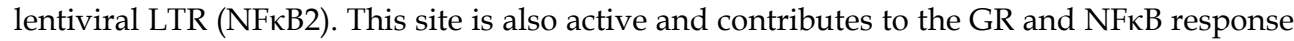
and is involved in activating the LTR in response to mitogenic stimuli (Mitra et al., 1995; Berkhout et al., 1989; Logan et al., 2004; Kilareski et al., 2009). The p50-p65-NFkB complex can bind both of these sites and enhance expression of HIV-1 genes. Further downstream, 
three AP-1 binding sites in U5 may also potentiate NFkB-dependent responses in integrated proviruses (Logan et al., 2004; Kilareski et al., 2009). Figure 2 shows the only direct binding sites for GR in retroviral LTR.

Thus the GR is a regulatory factor that can influence HIV-1 activity through multiple mechanisms, not only by its direct binding to the GRE, but also through its effects on NFkB and AP-1 signaling pathways. These influences can be both positive and negative. (Hapgood \& Tomasicchio, 2010; Kino et al., 1999; Ayyavoo et al., 1997a; Mirani et al., 2002) The overall effect of glucocorticoids on lentiviral promoter activity, therefore, can be difficult to predict. This may explain the confusing, and often contradictory, results on the effect of glucocorticoids on HIV-1 progression obtained by different research groups (Kino et al., 2000).

\section{Viral protein $\mathbf{R}$ potentiates the effect of glucocorticoid receptor}

In contrast to the relatively simple ways that gamma-retroviruses induce host cell infection, lentiviruses have evolved multiple strategies to induce a persistent infection in host cells. HIV-1 in particular, employs several strategies that rely on an array of virally encoded accessory proteins, including Vif, Vpr, Vpu, and Nef. Collectively, these proteins appear to manipulate host cell biology to ensure a favorable cellular environment for viral replication, transmission, dissemination, and immune evasion (Malim \& Emerman, 2008). One of them in particular, the 14-kDa HIV-1 viral protein $\mathrm{R}(\mathrm{Vpr})$, down-regulates the expression of genes involved in cell cycle/proliferation, DNA repair, tumor antigen presentation by the host cell, and immune activation factors, and upregulates many ribosomal and structural proteins required for viral propagation (Janket et al., 2004; Levy et al., 1994; Wu et al., 1995, Sherman et al., 2000). These changes can occur in the absence of other viral gene products, suggesting that Vpr can mediate its proviral effects partially, or perhaps solely, through modulation of the target cell environment (Ayyavoo et al., 1997a).

Vpr protein is present in high titers in the serum of AIDS patients and can be efficiently taken up from the extracellular medium by cells in vitro in a process that occurs independent of other HIV-1 proteins and also independent of cellular receptors. Following cellular uptake, Vpr can have multiple actions on the host cell GR signaling pathway, an interaction that can affect both the host cell and the virus. Two highly conserved leucine-rich domains within Vpr resemble the GR coactivator signature motif which allows Vpr to activate the GR in the absence in glucocorticoids (Sherman et al., 2000). As a result, the activated Vpr-GR complex translocates into the nucleus and induces the expression of glucocorticoidresponsive genes in a similar direction to that seen with dexamethasone in either the host cell or the viral promoters (Muthumani et al., 2006). Vpr can also activate the HIV-1 promoter without GR, directly binding to the viral SP-1 site in complexes with other activators (Kino et al., 2002, Kino et al., 2000, Amini et al., 2004). Thus, Vpr can stimulate the retroviral promoter leading to increased virus production and virion maturation. Experimentally it has been shown to induce virus expression in the peripheral blood mononuclear cells of HIV-infected individuals (Levy et al., 1994) and can directly induce Tcell receptor-triggered apoptosis. This effect, central to the ability of HIV-1 to deplete T cells, can be prevented by the inhibitory steroid hormone mifepristone (Ayyavoo et al., 1997b; Fakruddin \& Laurence, 2005). In addition to its effect on the lentiviral and the host cell promoters, Vpr also enhances expression of the beta-retroviral mouse mammary tumor virus (MMTV) promoter suggesting that $\mathrm{Vpr}$ could be used as an enhancer in retroviruses other than lentiviruses (Kino et al., 2002). 
Vpr interaction with the host cell's GR and subsequent ability to transactivate the HIV-1 LTR directly (i.e. in the absence of glucocorticoids), can be blocked by mifepristone. Mifepristone, also known as RU-486 is an abortifacient that has both anti-progestin and anti-glucocorticoid activity. It can bind and activate the GR-alpha primarily, but recent work suggests that it can also bind and translocate the GR-beta into the nucleus of Cos1 and U2OS cells, leading to upregulation of a number of genes (Lewis-Tuffin et al., 2007). In vitro, mifepristone was able to inhibit Vpr-mediated translocation of the HIV nucleoprotein preintegration complex into the host cell nucleus and block Vpr-induced apoptosis, cytokine production and T-cell proliferation (Schafer et al., 2006). This and other experimental observations led to the hypothesis that mifepristone could reduce viral synthesis in infected cells and therefore could reduce the pace of infection in vivo. A clinical trial examining the anti-HIV activity and safety of mifepristone on viral load, disease progression, and survival in HIV-1 infected individuals was begun in 2006 (Clinical trial number: NCT00352911). Final results of that trial have not yet been released, but interim results suggest no benefit of mifepristone in the primary endpoint of reducing HIV viral load at 28 days (Para et al., 2010).

\section{Role of glucocorticoid receptor in immune resonance, retroviral release and integration capability}

Glucocorticoids are among the most commonly prescribed drugs worldwide due to their profound anti-inflammatory and immunosuppressive activity (Herold et al., 2006; Kim et al., 2001; Janket et al., 2004). They control homeostasis of $\mathrm{T}$ cell monocytes/macrophages, osteoclasts, and dendritic cells by inducing their apoptosis or inhibiting maturation. Most, if not all, of these effects are mediated through their interactions with the GR (Herold et al., 2006). Activated GR can interfere with the signaling pathways of AP- 1 and NFkB, two key host transcription factors that regulate expression of pro-inflammatory genes and other genes involved in immune responses (Hapgood \& Tomasicchio, 2010; De Bosscher et al., 2003; Smoak \& Cidlowski, 2004)

Vpr enhances the immunosuppressive effect of endogenous and therapeutic glucocorticoids (Mirani et al., 2002; Kino et al., 1999). Vpr administered extracellularly potentiated the glucocorticoid-induced suppression of mRNA expression and secretion of IL-12 by dendritic cells (Kim et al., 2001). Vpr also potentiated the glucocorticoid-induced inhibition of other immunologically important cytokines such as IL-2, IL-10, TNF alpha and IL-4, all of which are NFкB -dependent (Fakruddin \& Laurence, 2005). Both the GR and Vpr are involved in the apoptosis in T cells and dendritic cells (Hapgood \& Tomasicchio, 2010; Bruland et al., 2003b). In addition, patients with AIDS and normal cortisol secretion have manifestations compatible with glucocorticoid hypersensitivity of the immune system, such as suppression of innate and cellular immunity.

Since the GR plays an important role in regulating viral promoter activity it is not surprising that it also affects viral particle production. Dexamethasone can stimulate the gammaretroviral promoter in viral producing cells (i.e. HEK 293 packaging cells) significantly increasing viral release into the cultured medium, a strategy that can be used to increase the viral titer for gene delivery applications (Solodushko et al., 2009). A similar effect can be seen with lentiviruses, but this is dependent on the formulation of glucocorticoid used and cell type infected. Hydrocortisone increased the efficacy of HIV-1 infection in fresh normal human peripheral blood mononuclear leukocytes whereas other corticosteroids (dexamethasone) and sex hormones, had no effect (Markham et al., 1986). 


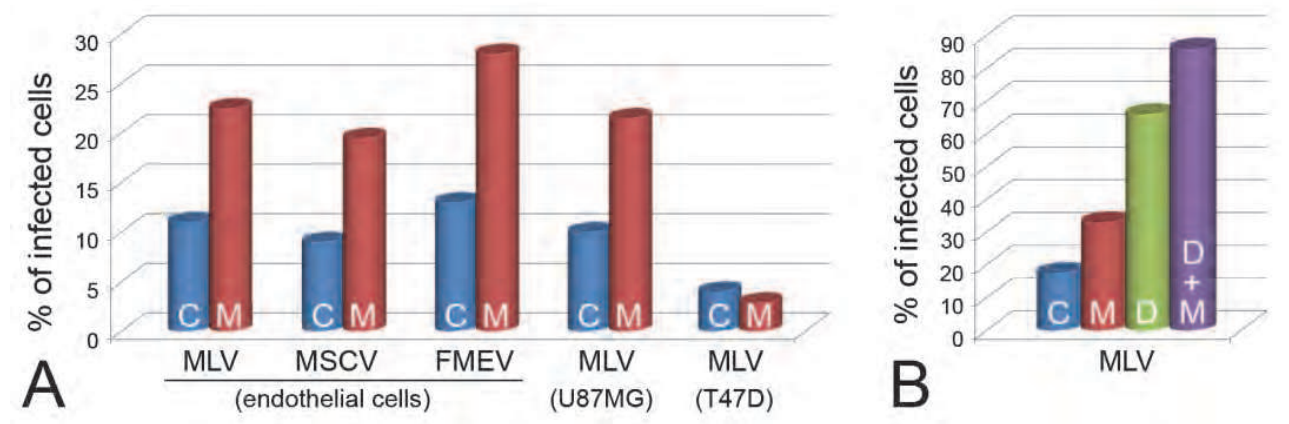

Fig. 3. A: The anti-glucocorticoid and anti-progestin agent, mifepristone, increased the integration efficiency of three gamma-retroviruses: moloney murine leukemia virus (MLV), murine stem cell virus (MSCV) and friend murine embryonic stem cell virus (FMEV). Target cells included: lung microvascular endothelial cells (expressing both functioning glucocorticoid (GR) and progesterone (PR) receptors), U87MG cells (lacking functioning GR) and T47D cells (lacking functioning PR). This effect was independent of viral titer. B: Infection efficiency of endothelial cells with MLV under four conditions: (C) control, no steroid treatment at time of virus propagation and infection; (D) virus was propagated and target cells were infected in the presence of glucocorticoid dexamethasone; $(\mathrm{M})$ virus was propagated with no steroids and target cells were infected in the presence of mifepristone; $(D+M)$ virus was propagated in the presence of dexamethasone followed by infection of target cells in the presence of dexamethasone and mifepristone.

We and others have demonstrated that dexamethasone can stimulate the gamma-retroviral LTR promoter and increase viral particle production in packaging cell lines. This effect could be blocked by the progestin and glucocorticoid antagonist, mifepristone. In a novel observation, we demonstrated that mifepristone could increase the infection efficiency of gamma-retroviruses in a number of different target cells including (human, rat, and mouse) vascular endothelial and smooth muscle cells, and epithelial cells. This effect was independent of viral titer. Later studies demonstrated that mifepristone had no effect on viral entry, viral survival or viral DNA synthesis, but increased gamma-retroviral infection efficiency by facilitating viral integration into the host genome (figure 3A). This effect appeared to be due to mifepristone's anti-glucocorticoid, but not its anti-progestin, activity since T47D cells lacking functioning GR did not demonstrate increased infection efficiency in the presence of mifepristone, whereas U87MG cells lacking functional progesterone receptors, did. Mifepristone had no effect on lentiviral integration into host cells, however. These results suggest that inhibition of the GR enhances retroviral integration into the host genome and indicates that cells may have a natural protection again retroviral infection that may be reduced by glucocorticoid receptor antagonists (Solodushko \& Fouty, 2010).

Based on these observations, we demonstrated that gamma-retroviral infection of target cells can be maximized by first incubating packaging cells with dexamethasone to increase the viral titre in the supernatant and then incubating target cells with mifepristone to improve integration of virus into the host genome (figure 3B) (Solodushko \& Fouty, 2010).

The predominantly cytoplasmic localization of the GR appears to be a specific obstacle for HIV replication by preventing its migration into the nucleus where it can complete the 
infectious process. The presence of both endogenous and exogenous glucocorticoids tends to increase the lentiviral infection efficiency of target cells. Resting peripheral mononuclear blood cells are not easily infected with HIV-1 due to a block, prior to integration, of the provirus into the host genome. Proviral integration increases after addition of a GR ligand (such as hydrocortisone or dexamethasone). This effect is confined to an early time period after incubation of the cells with the virus and requires the presence of the GR and the GR binding viral protein $\mathrm{Vpr}$ (Wiegers et al., 2008).

\section{Lessons for retroviral gene therapy}

Due to safety concerns, retroviral vectors are made replication incompetent by the removal of the gag, pol and env genes. As a result, while retroviral vectors are still capable of transducing cells and expressing the foreign (delivered) gene, they cannot produce infectious viral particles due to the lack of structural and enzymatic genes. To generate the retroviral vectors needed to deliver genes of interest to target cells, the gag, pol and env genes are stably introduced into retroviral-packaging (producing) cells. The presence of functioning LTRs, PBS, psi and PPT are required and sufficient for the proper function of most gamma-retroviral vectors whereas additional trans and cis elements are required for the proper function of lentiviruses. The genetic modifications required to transform wild type gamma-retroviruses and lentiviruses into vectors suitable for use in research and clinical trials can significantly alter their response to environmental signals. Since the retroviral life cycle is dependent somewhat on the function of the GR in host cells, retroviral gene delivery vectors derived from wild type retroviruses are also regulated by GR activity. While many regions of the wild type retroviral backbones genome can be altered to meet the demands of gene delivery, essential parts of the viral genome must be retained to allow transgene expression and vector (virus) production. An intact R and U5 regions of the LTR promoter are required for the virus to work. Parts of the U3 (enhancer) region of the promoter can be modified, deleted or replaced by other sequences, without significantly decreasing virus functionality, however. The U3 region of most retroviruses contains GRE and, in the case of lentiviruses, NFkB response elements as well. Removing these response elements will still allow the virus to function, but will alter its responsiveness to GR signaling pathways. Therefore vectors with full length LTR or truncated LTR that retain these GR responsive sequences, will behave like wild type viruses in response to GR activation whereas vectors in which they have been removed will appear non-responsive to GR activation.

The promoters of gamma-retroviral vectors with completely functional GRE are strongly stimulated when exposed to GR. This enhancing effect of activated GR on the LTR promoter in gamma-retroviruses can be exploited to increase viral production by packaging cells and also to increase expression of reporter or therapeutic genes in target cells once the viral genome is integrated. The net effect of activated GR (due to either glucocorticoids or Vpr) on LTR activity in lentiviruses is less predictable, however, due to the opposing effects of GR on the GRE and NFkB regulatory segments. Published data indicate that glucocorticoids can have either positive or negative effects on the LTR promoter in lentiviruses depending on the cell type, glucocorticoid formulation, and vector being studied (Soudeyns et al., 1993; Kolesnitchenko \& Snart, 1992; Kino et al., 2000; Mitra et al., 1995).

For the HIV-1 based vector, most of the accessory genes (Vif, Vpr, Vpu, Nef) as well as Tat and Rev have been deleted for safety reasons or separated from the packaging construct. Despite these deletions, this modified virus can still function as a gene delivery vector. 
While the absence of Vpr does not interfere with infection efficiency in most cell types, this protein can potentiate transduction of macrophages (Amado \& Chen, 1999; Heinzinger et al., 1994), muscle, and liver cells (Kafri et al., 1997; Blomer et al., 1997). In addition, Vpr is a known activator of lentiviral and cellular promoters and can also enhance activity of the MMLV LTR promoter by directly binding to p300/CBP coactivators (Kino et al., 2002). Since $\mathrm{Vpr}$ is deleted in most lentiviral vectors, its ability to enhance activation of the viral LTR and the host promoters is also eliminated. Vpr can enter cells independent of the virus, however, and can activate retroviral vectors even if it is not included in the vector. Vpr can block NFkB and AP-1 signaling, thus inducing immune suppression which increases the likelihood of successful retroviral stable infection of host cells in vivo. When using third generation lentiviral vectors which lack $\mathrm{Vpr}$, some investigators have delivered $\mathrm{Vpr}$ separately to increase the chances of a successful infection.

Self-inactivating (SIN) retroviral vectors are ones in which a region of the $3^{\prime}$ LTR that contains an enhancing region of the viral promoter is deleted. The complementary region in the 5'LTR is replaced by a promoter to allow transcription of the full-length viral genome. After integration into the host genome, the retroviral LTR becomes inactive allowing increased transgene expression from another internal promoter. This allows the placement of a stronger promoter such as cytomegalovirus (CMV) to increase transgene expression, or alternatively, to allow site-specific activation of the transgene such as when the internal promoter is the endothelial promoter, Tie2, which will only allow transgene expression in endothelial cells. Originally SIN vectors were thought to be safer for gene therapy because they lacked the retroviral enhancer element and therefore do not continue to replicate within the host genome. There is some debate about whether this is true or not, however (Bosticardo et al., 2009; Yu et al., 1986).

In SIN vectors, the role of the GR on viral promoter activity is further reduced because the GREs within the U3 region are also removed. To combat this limitation, the excised GRE can be restored within the second internal promoter. Even without restoring GREs in SIN vectors, however, activated GR continue to have an effect on lentiviral behavior due to the presence of GRE and NFkB responsive sequences in regions other than U3 (Soudeyns et al., 1993; Hapgood \& Tomasicchio, 2010; Mitra et al., 1995; Berkhout et al., 1989; Logan et al., 2004; Kilareski et al., 2009). GR, in cooperation with other regulatory proteins, can bind these sites and enhance AP-1 signaling since several AP-1 binding sites are present not only in U3, but in the U5 region of HIV-1 also. Since the R and U5 regions are not significantly altered in retroviral vectors due to their importance in viral function, these NFkB and AP-1 sites remain relatively intact even in SIN lentiviral vectors and therefore may contribute to residual LTR transcriptional activity (Logan et al., 2004; Kilareski et al., 2009; Logan et al., 2004)

Depending on the type of internal promoter used in SIN vectors, their enhancers may also have GRE or NFkB response elements. The most robust and popular internal promoters used in lentiviral vectors (such as CMV or SV-40) may also contain NFkB binding sites that increase promoter activity when NFkB is bound (Ross et al., 1991). Lentiviral Vpr can also increase the activity of CMV, SV-40 and many other internal promoters (Hiscott et al., 2001; Roux et al., 2000; Kim et al., 2007). Glucocorticoids can have different effects on these internal retroviral promoters if they are used with an intact LTR promoter, however, and this appears to be a function of cell type. For example, in bone marrow cells infected with a retroviral construction that contains a full length LTR and a second internal SV-40 promoter (which does not contain the GRE), dexamethasone suppresses SV-40 promoter activity, 
whereas in retrovirus-infected fibroblasts infected with the same retroviral vector, dexamethasone increased SV-40 activity (Akahane et al., 2002). Therefore, retroviral vectors with internal promoters should be designed individually depending on the cell type that needs to be infected and the effect of glucocorticoids on these vectors needs to be tested in each cell type. Understanding the distinct effects of modified vectors in different cell types is important for successful gene therapy (Derecka et al., 2006).

\section{Conclusions}

Gamma-retroviruses and lentiviruses are the most commonly used vectors for in vitro and in vivo gene delivery and both are responsive to activated GR. The GR signaling pathway is an important regulator of retroviral functionality through both its effects on the retrovirus and its effects on the target cell. In addition to its effects on the host cell and the retrovirus, glucocorticoids and activated GR can also dampen cellular immunity. This is particularly important when retroviruses are used as gene delivery vehicles in vivo. Once these wild type viruses are modified for gene delivery applications, however, the direction and magnitude of this GR response can be altered. Depending on what areas of the retroviral genome are changed, the effects of GR activation can vary greatly. In addition, the cell type infected contributes to the GR response making predictions about the effects of GR activators (i.e. glucocorticoids and Vpr) in specific cell types, difficult. Retroviral vectors therefore, need to be designed for a specific purpose and cell type and they must also be tested within the cell of interest under the conditions of interest to confirm the desired effect.

\section{Acknowledgements}

This work was supported, in part, by an American Heart Association Grant-in-Aid from the Greater Southeast Affiliate (09GRNT2260914).

\section{References}

Akahane, M., Kuriyama, S., Ohgushi, H., Akahane, T., Kawamura, K., Watanabe, S., Funakoshi, F., Yoshiji, H., Ikenaka, K. \& Takakura, Y. (2002). Enhancing and suppressing effects of dexamethasone on transgene expression in vitro. Int $\mathrm{J} \mathrm{Mol}$ Med, Vol. 10, No. 1, pp. 107-12.

Amado, R.G. \& Chen, I.S. (1999). Lentiviral vectors--the promise of gene therapy within reach? Science, Vol. 285, No. 5428, pp. 674-6.

Amini, S., Saunders, M., Kelley, K., Khalili, K. \& Sawaya, B.E. (2004). Interplay between HIV-1 Vpr and Sp1 modulates p21(WAF1) gene expression in human astrocytes. J Biol Chem, Vol. 279, No. 44, pp. 46046-56.

Ayyavoo, V., Mahalingam, S., Rafaeli, Y., Kudchodkar, S., Chang, D., Nagashunmugam, T., Williams, W.V. \& Weiner, D.B. (1997a). HIV-1 viral protein R (Vpr) regulates viral replication and cellular proliferation in T cells and monocytoid cells in vitro. $J$ Leukoc Biol, Vol. 62, No. 1, pp. 93-9.

Ayyavoo, V., Mahboubi, A., Mahalingam, S., Ramalingam, R., Kudchodkar, S., Williams, W.V., Green, D.R. \& Weiner, D.B. (1997b). HIV-1 Vpr suppresses immune activation and apoptosis through regulation of nuclear factor kappa B. Nat Med, Vol. 3, No. 10, pp. 1117-23. 
Berkhout, B., Silverman, R.H. \& Jeang, K.T. (1989). Tat trans-activates the human immunodeficiency virus through a nascent RNA target. Cell, Vol. 59, No. 2, pp. 273-82.

Blomer, U., Naldini, L., Kafri, T., Trono, D., Verma, I.M. \& Gage, F.H. (1997). Highly efficient and sustained gene transfer in adult neurons with a lentivirus vector. J Virol, Vol. 71, No. 9, pp. 6641-9.

Bosticardo, M., Ghosh, A., Du, Y., Jenkins, N.A., Copeland, N.G. \& Candotti, F. (2009). Selfinactivating retroviral vector-mediated gene transfer induces oncogene activation and immortalization of primary murine bone marrow cells. Mol Ther, Vol. 17, No. 11, pp. 1910-8.

Bruland, T., Lavik, L.A., Dai, H.Y. \& Dalen, A. (2003a). A glucocorticoid response element in the LTR U3 region of Friend murine leukaemia virus variant FIS-2 enhances virus production in vitro and is a major determinant for sex differences in susceptibility to FIS-2 infection in vivo. J Gen Virol, Vol. 84, No. Pt 4, pp. 907-16.

Bruland, T., Lavik, L.A., Dai, H.Y. \& Dalen, A. (2003b). Identification of Friend murine retrovirus-infected immune cells and studies of the effects of sex and steroid hormones in the early phase of infection. APMIS, Vol. 111, No. 9, pp. 878-90.

Buckingham, J.C. (2006). Glucocorticoids: exemplars of multi-tasking. Br J Pharmacol, Vol. 147 Suppl 1, pp. S258-68.

De Bosscher, K., Vanden Berghe, W. \& Haegeman, G. (2003). The interplay between the glucocorticoid receptor and nuclear factor-kappaB or activator protein-1: molecular mechanisms for gene repression. Endocr Rev, Vol. 24, No. 4, pp. 488-522.

Derecka, K., Wang, C.K. \& Flint, A.P. (2006). Interactions between the cytomegalovirus promoter and the estrogen response element: implications for design of estrogenresponsive reporter plasmids. J Biomol Tech, Vol. 17, No. 3, pp. 218-27.

Fakruddin, J.M. \& Laurence, J. (2005). HIV-1 Vpr enhances production of receptor of activated NF-kappaB ligand (RANKL) via potentiation of glucocorticoid receptor activity. Arch Virol, Vol. 150, No. 1, pp. 67-78.

Francke, U. \& Foellmer, B.E. (1989). The glucocorticoid receptor gene is in 5q31-q32 [corrected]. Genomics, Vol. 4, No. 4, pp. 610-2.

Ghosh, D. (1992). Glucocorticoid receptor-binding site in the human immunodeficiency virus long terminal repeat. J Virol, Vol. 66, No. 1, pp. 586-90.

Ghosh, S., May, M.J. \& Kopp, E.B. (1998). NF-kappa B and Rel proteins: evolutionarily conserved mediators of immune responses. Annu Rev Immunol, Vol. 16, pp. 225-60.

Hapgood, J.P. \& Tomasicchio, M. (2010). Modulation of HIV-1 virulence via the host glucocorticoid receptor: towards further understanding the molecular mechanisms of HIV-1 pathogenesis. Arch Virol, Vol. 155, No. 7, pp. 1009-19.

Hayashi, R., Wada, H., Ito, K. \& Adcock, I.M. (2004). Effects of glucocorticoids on gene transcription. Eur J Pharmacol, Vol. 500, No. 1-3, pp. 51-62.

Heinzinger, N.K., Bukinsky, M.I., Haggerty, S.A., Ragland, A.M., Kewalramani, V., Lee, M.A., Gendelman, H.E., Ratner, L., Stevenson, M. \& Emerman, M. (1994). The Vpr protein of human immunodeficiency virus type 1 influences nuclear localization of viral nucleic acids in nondividing host cells. Proc Natl Acad Sci U S A, Vol. 91, No. 15, pp. 7311-5.

Hermoso, M.A. \& Cidlowski, J.A. (2003). Putting the brake on inflammatory responses: the role of glucocorticoids. IUBMB Life, Vol. 55, No. 9, pp. 497-504. 
Herold, M.J., McPherson, K.G. \& Reichardt, H.M. (2006). Glucocorticoids in T cell apoptosis and function. Cell Mol Life Sci, Vol. 63, No. 1, pp. 60-72.

Hiscott, J., Kwon, H. \& Genin, P. (2001). Hostile takeovers: viral appropriation of the NFkappaB pathway. J Clin Invest, Vol. 107, No. 2, pp. 143-51.

Hollenberg, S.M., Weinberger, C., Ong, E.S., Cerelli, G., Oro, A., Lebo, R., Thompson, E.B., Rosenfeld, M.G. \& Evans, R.M. (1985). Primary structure and expression of a functional human glucocorticoid receptor cDNA. Nature, Vol. 318, No. 6047, pp. 63541.

Ito, K., Jazrawi, E., Cosio, B., Barnes, P.J. \& Adcock, I.M. (2001). p65-activated histone acetyltransferase activity is repressed by glucocorticoids: mifepristone fails to recruit HDAC2 to the p65-HAT complex. J Biol Chem, Vol. 276, No. 32, pp. 30208-15.

Jaalouk, D.E., Eliopoulos, N., Couture, C., Mader, S. \& Galipeau, J. (2000). Glucocorticoidinducible retrovector for regulated transgene expression in genetically engineered bone marrow stromal cells. Hum Gene Ther, Vol. 11, No. 13, pp. 1837-49.

Janket, M.L., Manickam, P., Majumder, B., Thotala, D., Wagner, M., Schafer, E.A., Collman, R.G., Srinivasan, A. \& Ayyavoo, V. (2004). Differential regulation of host cellular genes by HIV-1 viral protein R (Vpr): cDNA microarray analysis using isogenic virus. Biochem Biophys Res Commun, Vol. 314, No. 4, pp. 1126-32.

Kafri, T., Blomer, U., Peterson, D.A., Gage, F.H. \& Verma, I.M. (1997). Sustained expression of genes delivered directly into liver and muscle by lentiviral vectors. Nat Genet, Vol. 17, No. 3, pp. 314-7.

Kilareski, E.M., Shah, S., Nonnemacher, M.R. \& Wigdahl, B. (2009). Regulation of HIV-1 transcription in cells of the monocyte-macrophage lineage. Retrovirology, Vol. 6, pp. 118.

Kim, K.D., Choe, Y.K., Choe, I.S. \& Lim, J.S. (2001). Inhibition of glucocorticoid-mediated, caspase-independent dendritic cell death by CD40 activation. J Leukoc Biol, Vol. 69, No. 3, pp. 426-34.

Kim, K.I., Kang, J.H., Chung, J.K., Lee, Y.J., Jeong, J.M., Lee, D.S. \& Lee, M.C. (2007). Doxorubicin enhances the expression of transgene under control of the CMV promoter in anaplastic thyroid carcinoma cells. J Nucl Med, Vol. 48, No. 9, pp. 155361.

Kino, T., Gragerov, A., Kopp, J.B., Stauber, R.H., Pavlakis, G.N. \& Chrousos, G.P. (1999). The HIV-1 virion-associated protein vpr is a coactivator of the human glucocorticoid receptor. J Exp Med, Vol. 189, No. 1, pp. 51-62.

Kino, T., Gragerov, A., Slobodskaya, O., Tsopanomichalou, M., Chrousos, G.P. \& Pavlakis, G.N. (2002). Human immunodeficiency virus type 1 (HIV-1) accessory protein Vpr induces transcription of the HIV-1 and glucocorticoid-responsive promoters by binding directly to p300/CBP coactivators. J Virol, Vol. 76, No. 19, pp. 9724-34.

Kino, T., Kopp, J.B. \& Chrousos, G.P. (2000). Glucocorticoids suppress human immunodeficiency virus type-1 long terminal repeat activity in a cell type-specific, glucocorticoid receptor-mediated fashion: direct protective effects at variance with clinical phenomenology. J Steroid Biochem Mol Biol, Vol. 75, No. 4-5, pp. 283-90.

Kolesnitchenko, V. \& Snart, R.S. (1992). Regulatory elements in the human immunodeficiency virus type 1 long terminal repeat LTR (HIV-1) responsive to steroid hormone stimulation. AIDS Res Hum Retroviruses, Vol. 8, No. 12, pp. 197780.

Lech, P. \& Somia, N.V. (2008). Retrovirus vectors. Contrib Nephrol, Vol. 159, pp. 30-46. 
Levy, D.N., Refaeli, Y., MacGregor, R.R. \& Weiner, D.B. (1994). Serum Vpr regulates productive infection and latency of human immunodeficiency virus type 1. Proc Natl Acad Sci U S A, Vol. 91, No. 23, pp. 10873-7.

Lewis-Tuffin, L.J., Jewell, C.M., Bienstock, R.J., Collins, J.B. \& Cidlowski, J.A. (2007). Human glucocorticoid receptor beta binds RU-486 and is transcriptionally active. Mol Cell Biol, Vol. 27, No. 6, pp. 2266-82.

Logan, A.C., Haas, D.L., Kafri, T. \& Kohn, D.B. (2004). Integrated self-inactivating lentiviral vectors produce full-length genomic transcripts competent for encapsidation and integration. J Virol, Vol. 78, No. 16, pp. 8421-36.

Lu, N.Z., Wardell, S.E., Burnstein, K.L., Defranco, D., Fuller, P.J., Giguere, V., Hochberg, R.B., McKay, L., Renoir, J.M., Weigel, N.L., Wilson, E.M., McDonnell, D.P. \& Cidlowski, J.A. (2006). International Union of Pharmacology. LXV. The pharmacology and classification of the nuclear receptor superfamily: glucocorticoid, mineralocorticoid, progesterone, and androgen receptors. Pharmacol Rev, Vol. 58, No. 4, pp. 782-97.

Malim, M.H. \& Emerman, M. (2008). HIV-1 accessory proteins--ensuring viral survival in a hostile environment. Cell Host Microbe, Vol. 3, No. 6, pp. 388-98.

Markham, P.D., Salahuddin, S.Z., Veren, K., Orndorff, S. \& Gallo, R.C. (1986). Hydrocortisone and some other hormones enhance the expression of HTLV-III. Int J Cancer, Vol. 37, No. 1, pp. 67-72.

Meijsing, S.H., Pufall, M.A., So, A.Y., Bates, D.L., Chen, L. \& Yamamoto, K.R. (2009). DNA binding site sequence directs glucocorticoid receptor structure and activity. Science, Vol. 324, No. 5925, pp. 407-10.

Mirani, M., Elenkov, I., Volpi, S., Hiroi, N., Chrousos, G.P. \& Kino, T. (2002). HIV-1 protein Vpr suppresses IL-12 production from human monocytes by enhancing glucocorticoid action: potential implications of Vpr coactivator activity for the innate and cellular immunity deficits observed in HIV-1 infection. J Immunol, Vol. 169, No. 11, pp. 6361-8.

Mitra, D., Sikder, S.K. \& Laurence, J. (1995). Role of glucocorticoid receptor binding sites in the human immunodeficiency virus type 1 long terminal repeat in steroid-mediated suppression of HIV gene expression. Virology, Vol. 214, No. 2, pp. 512-21.

Muthumani, K., Choo, A.Y., Zong, W.X., Madesh, M., Hwang, D.S., Premkumar, A., Thieu, K.P., Emmanuel, J., Kumar, S., Thompson, C.B. \& Weiner, D.B. (2006). The HIV-1 $\mathrm{Vpr}$ and glucocorticoid receptor complex is a gain-of-function interaction that prevents the nuclear localization of PARP-1. Nat Cell Biol, Vol. 8, No. 2, pp. 170-9.

Nissen, R.M. \& Yamamoto, K.R. (2000). The glucocorticoid receptor inhibits NFkappaB by interfering with serine-2 phosphorylation of the RNA polymerase II carboxyterminal domain. Genes Dev, Vol. 14, No. 18, pp. 2314-29.

Pages, J.C., Loux, N., Farge, D., Briand, P. \& Weber, A. (1995). Activation of Moloney murine leukemia virus LTR enhances the titer of recombinant retrovirus in psi CRIP packaging cells. Gene Ther, Vol. 2, No. 8, pp. 547-51.

Para, M.F., Schouten, J., Rosenkranz, S.L., Yu, S., Weiner, D., Tebas, P., White, C.J., Reeds, D., Lertora, J., Patterson, K.B., Daar, E.S., Cavert, W. \& Brizz, B. (2010). Phase I/II trial of the anti-HIV activity of mifepristone in HIV-infected subjects ACTG 5200. J Acquir Immune Defic Syndr, Vol. 53, No. 4, pp. 491-5. 
Pratt, W.B., Morishima, Y., Murphy, M. \& Harrell, M. (2006). Chaperoning of glucocorticoid receptors. Handb Exp Pharmacol, No. 172, pp. 111-38.

Rhen, T. \& Cidlowski, J.A. (2005). Antiinflammatory action of glucocorticoids--new mechanisms for old drugs. N Engl J Med, Vol. 353, No. 16, pp. 1711-23.

Rodriguez, J.J. \& Goff, S.P. (2010). Xenotropic murine leukemia virus-related virus establishes an efficient spreading infection and exhibits enhanced transcriptional activity in prostate carcinoma cells. J Virol, Vol. 84, No. 5, pp. 2556-62.

Ross, E.K., Buckler-White, A.J., Rabson, A.B., Englund, G. \& Martin, M.A. (1991). Contribution of NF-kappa B and Sp1 binding motifs to the replicative capacity of human immunodeficiency virus type 1: distinct patterns of viral growth are determined by T-cell types. J Virol, Vol. 65, No. 8, pp. 4350-8.

Roux, P., Alfieri, C., Hrimech, M., Cohen, E.A. \& Tanner, J.E. (2000). Activation of transcription factors NF-kappaB and NF-IL-6 by human immunodeficiency virus type 1 protein $\mathrm{R}$ (Vpr) induces interleukin-8 expression. J Virol, Vol. 74, No. 10, pp. 4658-65.

Rusmevichientong, A. \& Chow, S.A. (2010). Biology and pathophysiology of the new human retrovirus XMRV and its association with human disease. Immunol Res, Vol. 48, No. 1-3, pp. 27-39.

Schafer, E.A., Venkatachari, N.J. \& Ayyavoo, V. (2006). Antiviral effects of mifepristone on human immunodeficiency virus type-1 (HIV-1): targeting $\mathrm{Vpr}$ and its cellular partner, the glucocorticoid receptor (GR). Antiviral Res, Vol. 72, No. 3, pp. 224-32.

Sherman, M.P., de Noronha, C.M., Pearce, D. \& Greene, W.C. (2000). Human immunodeficiency virus type $1 \mathrm{Vpr}$ contains two leucine-rich helices that mediate glucocorticoid receptor coactivation independently of its effects on $G(2)$ cell cycle arrest. J Virol, Vol. 74, No. 17, pp. 8159-65.

Smoak, K.A. \& Cidlowski, J.A. (2004). Mechanisms of glucocorticoid receptor signaling during inflammation. Mech Ageing Dev, Vol. 125, No. 10-11, pp. 697-706.

Solodushko, V., Bitko, V. \& Fouty, B. (2009). Dexamethasone and mifepristone increase retroviral infectivity through different mechanisms. Am J Physiol Lung Cell Mol Physiol, Vol. 297, No. 3, pp. L538-45.

Solodushko, V. \& Fouty, B. (2010). Mifepristone increases gamma-retroviral infection efficiency by enhancing the integration of virus into the genome of infected cells. Gene Ther, Vol. 17, No. 10, pp. 1253-61.

Somia, N. \& Verma, I.M. (2000). Gene therapy: trials and tribulations. Nat Rev Genet, Vol. 1, No. 2, pp. 91-9.

Soudeyns, H., Geleziunas, R., Shyamala, G., Hiscott, J. \& Wainberg, M.A. (1993). Identification of a novel glucocorticoid response element within the genome of the human immunodeficiency virus type 1. Virology, Vol. 194, No. 2, pp. 758-68.

Telesnitsky, A. (2010). Retroviruses: Molecular Biology, Genomics and Pathogenesis. Future Virol, Vol. 5, No. 5, pp. 539-543.

Thomas, C.E., Ehrhardt, A. \& Kay, M.A. (2003). Progress and problems with the use of viral vectors for gene therapy. Nat Rev Genet, Vol. 4, No. 5, pp. 346-58.

Tuckermann, J.P., Reichardt, H.M., Arribas, R., Richter, K.H., Schutz, G. \& Angel, P. (1999). The DNA binding-independent function of the glucocorticoid receptor mediates repression of AP-1-dependent genes in skin. J Cell Biol, Vol. 147, No. 7, pp. 1365-70. 
Wiegers, K., Schwarck, D., Reimer, R. \& Bohn, W. (2008). Activation of the glucocorticoid receptor releases unstimulated PBMCs from an early block in HIV-1 replication. Virology, Vol. 375, No. 1, pp. 73-84.

Wu, B.Y., Woffendin, C., Duckett, C.S., Ohno, T. \& Nabel, G.J. (1995). Regulation of human retroviral latency by the NF-kappa B/I kappa B family: inhibition of human immunodeficiency virus replication by I kappa B through a Rev-dependent mechanism. Proc Natl Acad Sci U S A, Vol. 92, No. 5, pp. 1480-4.

Yi, Y., Hahm, S.H. \& Lee, K.H. (2005). Retroviral gene therapy: safety issues and possible solutions. Curr Gene Ther, Vol. 5, No. 1, pp. 25-35.

Yu, S.F., von Ruden, T., Kantoff, P.W., Garber, C., Seiberg, M., Ruther, U., Anderson, W.F., Wagner, E.F. \& Gilboa, E. (1986). Self-inactivating retroviral vectors designed for transfer of whole genes into mammalian cells. Proc Natl Acad Sci U S A, Vol. 83, No. 10, pp. 3194-8. 


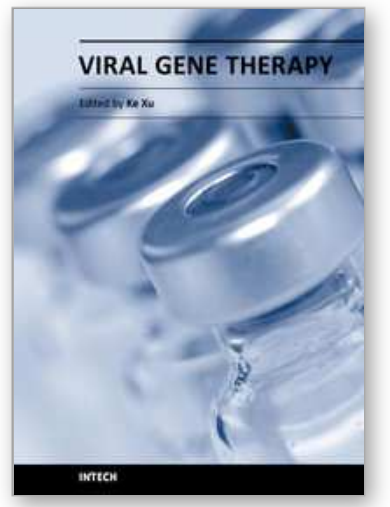

\author{
Viral Gene Therapy \\ Edited by Dr. Ke Xu
}

ISBN 978-953-307-539-6

Hard cover, 450 pages

Publisher InTech

Published online 20, July, 2011

Published in print edition July, 2011

The development of technologies that allow targeting of specific cells has progressed substantially in recent years for several types of vectors, particularly viral vectors, which have been used in $70 \%$ of gene therapy clinical trials. Particular viruses have been selected as gene delivery vehicles because of their capacities to carry foreign genes and their ability to efficiently deliver these genes associated with efficient gene expression. This book is designed to present the most recent advances in viral gene therapy

\title{
How to reference
}

In order to correctly reference this scholarly work, feel free to copy and paste the following:

Brian Fouty and Victor Solodushko (2011). The Glucocorticoid Receptor in Retroviral Infection, Viral Gene Therapy, Dr. Ke Xu (Ed.), ISBN: 978-953-307-539-6, InTech, Available from:

http://www.intechopen.com/books/viral-gene-therapy/the-glucocorticoid-receptor-in-retroviral-infection

\section{INTECH}

open science | open minds

\author{
InTech Europe \\ University Campus STeP Ri \\ Slavka Krautzeka 83/A \\ 51000 Rijeka, Croatia \\ Phone: +385 (51) 770447 \\ Fax: +385 (51) 686166 \\ www.intechopen.com
}

\author{
InTech China \\ Unit 405, Office Block, Hotel Equatorial Shanghai \\ No.65, Yan An Road (West), Shanghai, 200040, China \\ 中国上海市延安西路65号上海国际贵都大饭店办公楼405单元 \\ Phone: +86-21-62489820 \\ Fax: $+86-21-62489821$
}


(C) 2011 The Author(s). Licensee IntechOpen. This chapter is distributed under the terms of the Creative Commons Attribution-NonCommercialShareAlike-3.0 License, which permits use, distribution and reproduction for non-commercial purposes, provided the original is properly cited and derivative works building on this content are distributed under the same license. 